\title{
ram \\ Cellulose Nanomaterials as a Future, Sustainable and Renewable Material
}

\author{
Hoang Thi Phuong ${ }^{1}$, Nguyen Kim Thoa ${ }^{2}$, Phung Thi Anh Tuyet ${ }^{1}$, Quyen Nguyen Van ${ }^{3, *}$ and Yen Dao Hai ${ }^{1, *}$ \\ 1 Institute of Chemistry, Vietnam Academy of Science and Technology, 18 Hoang Quoc Viet, Cau Giay, \\ Hanoi 11307, Vietnam; hoangphuong15@gmail.com (H.T.P.); phungthianhtuyet98@gmail.com (P.T.A.T.) \\ 2 Institute of Biotechnology, Vietnam Academy of Science and Technology, 18 Hoang Quoc Viet, Cau Giay, \\ Hanoi 11307, Vietnam; nkthoa@ibt.ac.vn \\ 3 Department of Advanced Materials Science and Nanotechnology, Vietnam Academy of Science and \\ Technology, University of Science and Technology of Hanoi (USTH), 18 Hoang Quoc Viet, Cau Giay, \\ Hanoi 11307, Vietnam \\ * Correspondence: Quyen.cat.ze@gmail.com (Q.N.V.); hoasinhmoitruong.vast@gmail.com (Y.D.H.)
}

check for updates

Citation: Phuong, H.T.; Thoa, N.K.; Tuyet, P.T.A.; Van, Q.N.; Hai, Y.D. Cellulose Nanomaterials as a Future, Sustainable and Renewable Material. Crystals 2022, 12, 106. https:// doi.org/10.3390/cryst12010106 Academic Editors: Adele Moatti, Jeffery A. Aguiar and Ritesh Sachan

Received: 30 November 2021

Accepted: 7 January 2022

Published: 14 January 2022

Publisher's Note: MDPI stays neutral with regard to jurisdictional claims in published maps and institutional affiliations.

Copyright: (c) 2022 by the authors. Licensee MDPI, Basel, Switzerland. This article is an open access article distributed under the terms and conditions of the Creative Commons Attribution (CC BY) license (https:// creativecommons.org/licenses/by/ $4.0 /)$.

\begin{abstract}
Cellulose nanomaterials (CNs) are renewable, bio-derived materials that can address not only technological challenges but also social impacts. This ability results from their unique properties, for example, high mechanical strength, high degree of crystallinity, biodegradable, tunable shape, size, and functional surface chemistry. This minireview provides chemical and physical features of cellulose nanomaterials and recent developments as an adsorbent and an antimicrobial material generated from bio-renewable sources.
\end{abstract}

Keywords: cellulose nanomaterial; nanocellulose adsorbent; cellulose nanocrystal

\section{Introduction}

Cellulose nanomaterials (CNs) hold many interesting properties, for example, high mechanical strength, reinforcing capabilities, biodegradable, environmentally friendly, and self-assembly in aqueous media which arises from its tunable shape, size, surface chemistry [1-9]. CNs can be considered as one type of natural polysaccharides that are widely used as nanocarriers to effectively remove dyes [10] or in the pharmaceutical field as drug delivery [11]. Innovative technology and applications utilizing cellulose nanomaterials, for example, in antimicrobial materials, heavy metals, and dyes and adsorbents, have attracted tremendous efforts during the past few decades [2-4,6,12].

Figure 1 presents an exponential increase in the number of publications on CNs including journal articles, books, or book chapters count and also patent documents collected from the Lens website with "nanocellulose" keywords. In the last ten years, the publication count on journal articles was increased by approximately 16 times from 929 in 2010 to 14,660 in 2020 and the filed and granted patents were also increased by 23 times in 10 years from 2010 to 2020. CNs have emerged as an ideal nanomaterial for sustainable development which satisfies several criteria: (i) it can be isolated easily from renewable cellulosic sources in high yield, environmentally friendly, and economically affordable; (ii) CNs are proven to have a low toxicity; in some cases, non-toxicity to human beings and biodegrade in nature and (iii), several chemical and mechanical methods are performed on nanocellulose to enhance its physical properties such as ionic conductivity, mechanical strength, thus greatly expanding their applications. For example, cellulose nanomaterials have Young's modulus in the range 20 to $50 \mathrm{GPa}$ and a large surface (up to a few hundreds of square meters per gram) associated with a great amount of the hydroxyl group, which eventually make them promising nanomaterials in biomedicine, environment, and high-end products $[1,4,8,13,14]$. Therefore, research on different aspects of cellulose nanomaterials, including extending possible applications in various industries, and their production techniques, has quickly increased. 

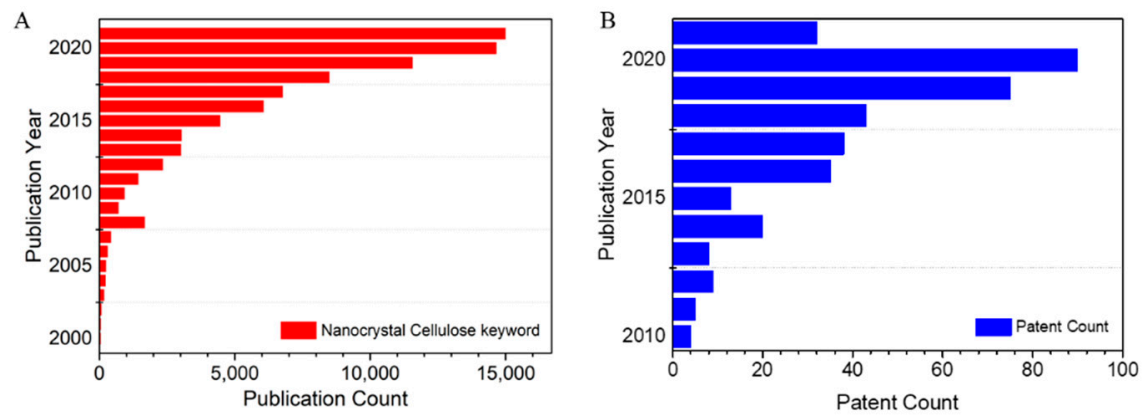

Figure 1. (A) Publications (journal articles and book/book chapters) and (B) Patent (filed and granted) documents related to nanocrystal cellulose.

This mini-review highlights cellulose nanomaterials' most important chemical and physical aspects and their relation to some emerging possible applications of CNs. Several other reviews on cellulose nanomaterials can be found in the literature. We will first provide a short description of the structure of cellulose nanomaterials and then strategies to functionalize $\mathrm{CNs}$ and finally end up with a description of two interesting applications, particularly sustainable, renewable adsorbents and antimicrobial materials.

\section{Nanocrystal Cellulose}

\subsection{Structure of Cellulose}

Cellulose is the most abundant renewable biomaterial produced in the biosphere, as it is the main component in wood (40-4\%) and other plant-based materials (up to $90 \%)[9,13,15-18]$. The annual production of cellulose is estimated to be approximately $10^{11}-10^{12}$ tons of total annual biomass production. It is widely agreed that cellulose is a fibrous, water-insoluble polymer playing an essential role in maintaining the structure of plant cell walls.

In 1838, Anselme Payen discovered a fibrous solid, first named cellulose by the French academy, remaining after several chemical treatment steps were applied to various plant tissues. He reported the molecular formula of the fibrous solid as $\mathrm{C}_{6} \mathrm{H}_{10} \mathrm{O}_{5}$ using elemental analysis $[9,18]$. Scheme 1 presents the molecular structure of cellulose, namely carbohydrate polymer, generated from repeating of $\beta$-1,4-linked-D-glucopyranose molecules, a chair conformation $[9,18]$. These repeating units are covalently linked through acetal functions between the $\mathrm{OH}$ group of $\mathrm{C} 4$ and the $\mathrm{C} 1$ carbon atom ( $\beta-1,4$-glucan). It is widely agreed that Cellulose is an extensive, linear chain polymer with a large number of hydroxyl groups (three per anhydroglucose, AGU, unit) presented in the thermodynamically preferred ${ }^{4} \mathrm{C}_{1}$ configuration. The repeating unit is frequently defined as a dimer of glucose, known as cellobiose (shown in Scheme 1). The length of cellulose or the degree of polymerization, DP, strongly depends on the origin and treatment of the raw material. The DP value of wood pulp is typically 300 to 1700 while cotton and other planted fibers have DP values in the 800-10,000 range which strongly depends on the treatment; cellulose generated by bacteria has the same DP values. Cellulose fibers usually contain 250 to 500 repeating units per chain $[9,18]$.

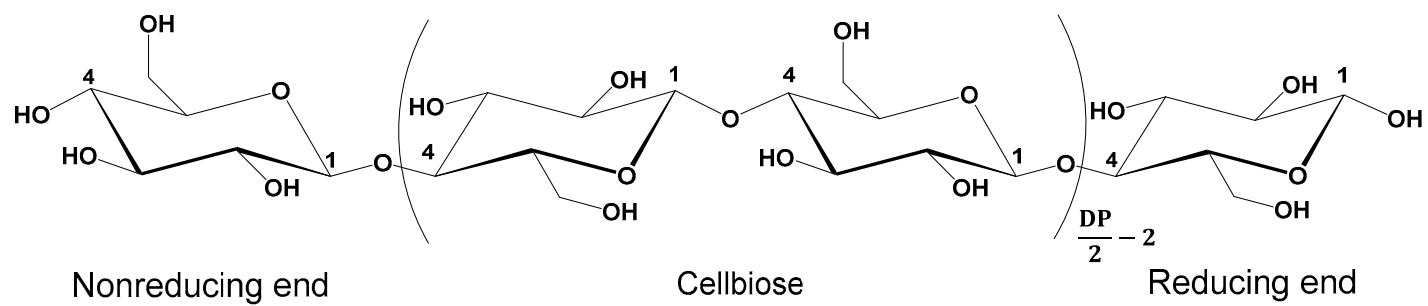

Scheme 1. Chemical structure of individual cellulose chain with DP known as degree of polymerization. 
It is agreed that at one end, the cellulose chain consists of a d-glucose unit with an original C4-OH group, known as a nonreducing end, and at the other end, a d-glucose unit with the aldehyde structure $(\mathrm{C} 1-\mathrm{OH})$, sometimes named as the reducing end, is presented. Moreover, cellulose produced by bleaching wood pulp may contain additional carbonyl or carboxyl groups at the $\mathrm{C} 6$ position. These functional groups play an important role in determining the cellulose properties such as the hydrophilicity, chirality, degradability, and broad chemical properties resulting from the high donor reactivity of the hydroxyl, $\mathrm{OH}$, groups $[5,18,19]$.

\subsection{Cellulose in Solid-State}

Cellulose does not exist as an isolated individual chain, instead, it is usually observed as assemblies of individual cellulose chain-forming fibers (30 to 100 chains) in nature $[2,3,9,15,18]$. The assembly phenomenon can occur via van der Waal's forces and both intra- and inter-molecular hydrogen bonding. Typically, individual cellulose chains assemblies are brought together into an elementary fibril (protofibrils), which then assemble into larger units called microfibrils with the cross-dimension in the range of 2 to $20 \mathrm{~nm}$, and these microfibrils are eventually packed into the cellulose fibers as shown in Figure 2A. The numerous possible applications of cellulose are based on its morphology defined by elementary fibrils, microfibrils, and microfibrillar bands and the chemical functional group on its surface. The lateral dimension of these units is in the range of 1.5 to $3.5 \mathrm{~nm}$ for elementary fibrils, 10 to $30 \mathrm{~nm}$ for microfibrils, and on the order of $100 \mathrm{~nm}$ for microfibrillar bands. The length of microfibrils is in the range of a few hundred nanometers to the micrometer, $\mu \mathrm{m}[5,20]$.
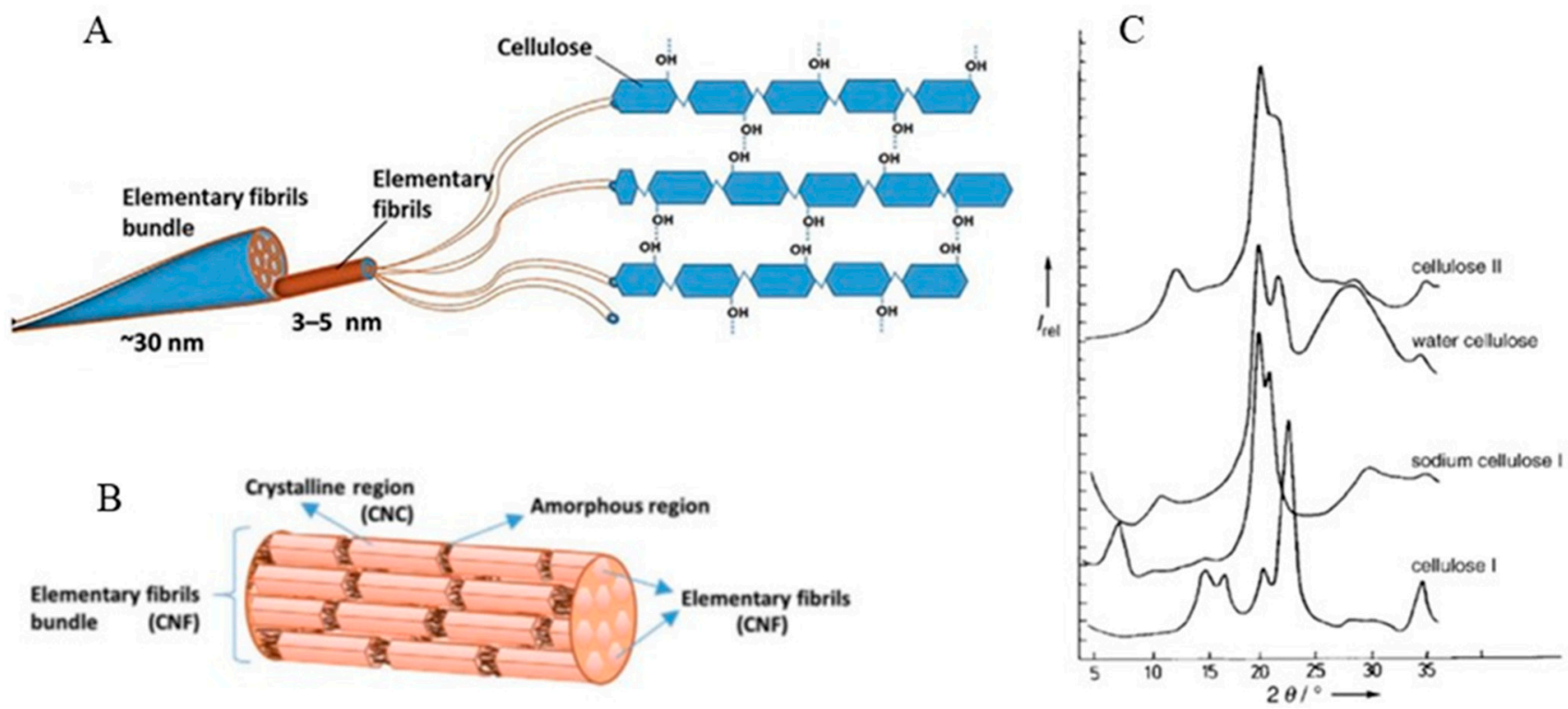

Figure 2. (A) Hierarchical cellulose fibrils. (B) Schematic of a cellulose bundle showing the organization of crystalline and amorphous regions (Reproduced with permission from authors [21]. (C) X-ray wide angle scattering of cellulose crystallinity phase transformation (Reproduced with permission from authors [21,22].

As described in the molecular structure of cellulose in Scheme 1, the H-bonding network forming between the hydroxyl groups and molecular orientation in cellulose fibers can vary widely, which results in cellulose polymorphs or allomorphs, depending on several parameters such as cellulosic source, method of extraction, or pretreatment and treatment. Another domain of cellulose fiber that could not be stabilized laterally through $\mathrm{H}$-bonding would form disordered and less organized segments, as illustrated in Figure 2B. Six interconvertible polymorphs of cellulose, namely, I, II, III, $\mathrm{III}_{\mathrm{II}}$, IV $\mathrm{I}$, and $\mathrm{IV}_{\mathrm{II}}$, have been identified $[18,19,21]$. Cellulose I is thermodynamically metastable and can be converted 
to either cellulose II or III. Cellulose II is known as the most stable structure, and it has a monoclinic structure and has been used to make cellophane (transparent films). Cellulose III can be produced from Cellulose I and II by liquid ammonia treatments, and subsequent thermal treatments can then be applied to form Cellulose IV. Natural cellulose is usually found in the form of cellulose $\mathrm{I}$, including cellulose $\mathrm{I}_{\alpha}$ and cellulose $\mathrm{I}_{\beta}$ discovered in 1984 by cross-polarization magic angle spinning (CP-MAS). $\mathrm{I}_{\alpha}$, a metastable phase, can be transformed into the more thermodynamically stable $\mathrm{I}_{\beta}$ phase by hydrothermal treatments (at $260{ }^{\circ} \mathrm{C}$ ) in alkaline solution or high-temperature treatment in organic solvents. Depending on the condition used, [21,22] cellulose I can be converted into various crystalline forms, as shown in Figure 2C.

In general, these two allomorphs coexist in different ratios: Cellulose $\mathrm{I} \alpha$ is dominated in primitive organisms like bacteria and algae, while in higher plants both I $\alpha$ and I $\beta$ are equally contributed $[8,23]$. In general, the crystalline structure of cellulose I $\alpha$ has a triclinic P1 unit cell containing only one chain per unit cell and the unit cell parameters are $a=6.717 \AA$, $\mathrm{b}=5.962 \AA, \mathrm{c}=10.400 \AA, \alpha=118.08^{\circ}, \beta=114.80^{\circ}$, and $\gamma=80.37^{\circ}$, whereas cellulose I $\beta$ exists in a monoclinic P21 unit cell having two cellulose chains per unit cell with the unit cell parameters: $a=7.784 \AA, b=8.201 \AA, c=10.38 \AA, \alpha=118^{\circ}, \beta=90^{\circ}$, and $\gamma=96.5^{\circ}$. Despite the differences in the crystal structure, the shifts in the cellulose chain arrangement in both structures are small, and the main difference is the relative displacement of the cellulose chain along the hydrogen-bonded planes.

The hydrogen bonding within cellulose $I$, both $I_{\alpha}$ and $I_{\beta}$, is important as it controls the physical properties of the polymorphs. The intra- and interchain hydrogen bonding are most recognized within the $(110)_{\mathrm{t}}$ and $(200)_{\mathrm{m}}$ planes, namely the hydrogen-bonded planes. The intrachain hydrogen bonding is dominated by the strong O3-H ... O5 bond, this configuration is widely agreed in the literature $[3,5]$. This intrachain hydrogen bonding is in charge of the high axial chain stiffness. The interchain hydrogen bonding within other planes is subsequently lower, and the van der Waal force is usually considered to be significantly strong between cellulose chains. It is also agreed that the number of the interchain hydrogen bonds in $\mathrm{I}_{\beta}$ is greater than in the $\mathrm{I}_{\alpha}$ polymorph which causes the good stability of $\mathrm{I}_{\beta}$ compared to $\mathrm{I}_{\alpha}$.

\section{Preparation of Cellulose Nanomaterials}

The main process to isolate CNs summarized in Table 1 will be briefly described here. The details can be found in the literature $[1,5,8,9,20]$. The most common protocol to isolate CNs is to hydrolyze and esterify cellulose in concentrated sulfuric acid within a short time $(<2 \mathrm{~h}$ ) with high yields (up to $75 \%$ ). It is widely agreed that the high proton concentration in concentrated acid will hydrolyze the glycosidic bonds faster in less ordered regimes of cellulose fiber. These bonds are broken, and the cellulose chain or degree polymerization will be shortened until the disordered regions have been partially degraded. To an extreme extent, the cellulose could be completely degraded into glucose molecules. Afterward, the CNs functionalized with the sulfate group can be isolated by centrifugation and dialysis, respectively. Besides sulfuric acid, several mineral acids have been used to produce CNs, such as hydrochloric acid, hydrobromic acid, and phosphoric acid, which can produce CNs with high degrees of crystallinity in high yields [20]. However, up to now, hydrolysis with sulfuric acid is still the best method since it allows to produce the CNs with high colloidal stability, uniform nanoscale length, and high crystallinity. Phosphorylation of nanocellulose has recently received particular efforts since phosphorylated CNs associated with a negative charge, $-\mathrm{OP}(\mathrm{OH}) \mathrm{O}_{2}{ }^{-}$, on its surface can be produced in good yield, and environmentally friendly $[24,25]$. 
Table 1. Common production method of cellulose nanomaterial, TEMPO-(2,2,6,6-tetramethylpiperi din-1-yl) oxyl.

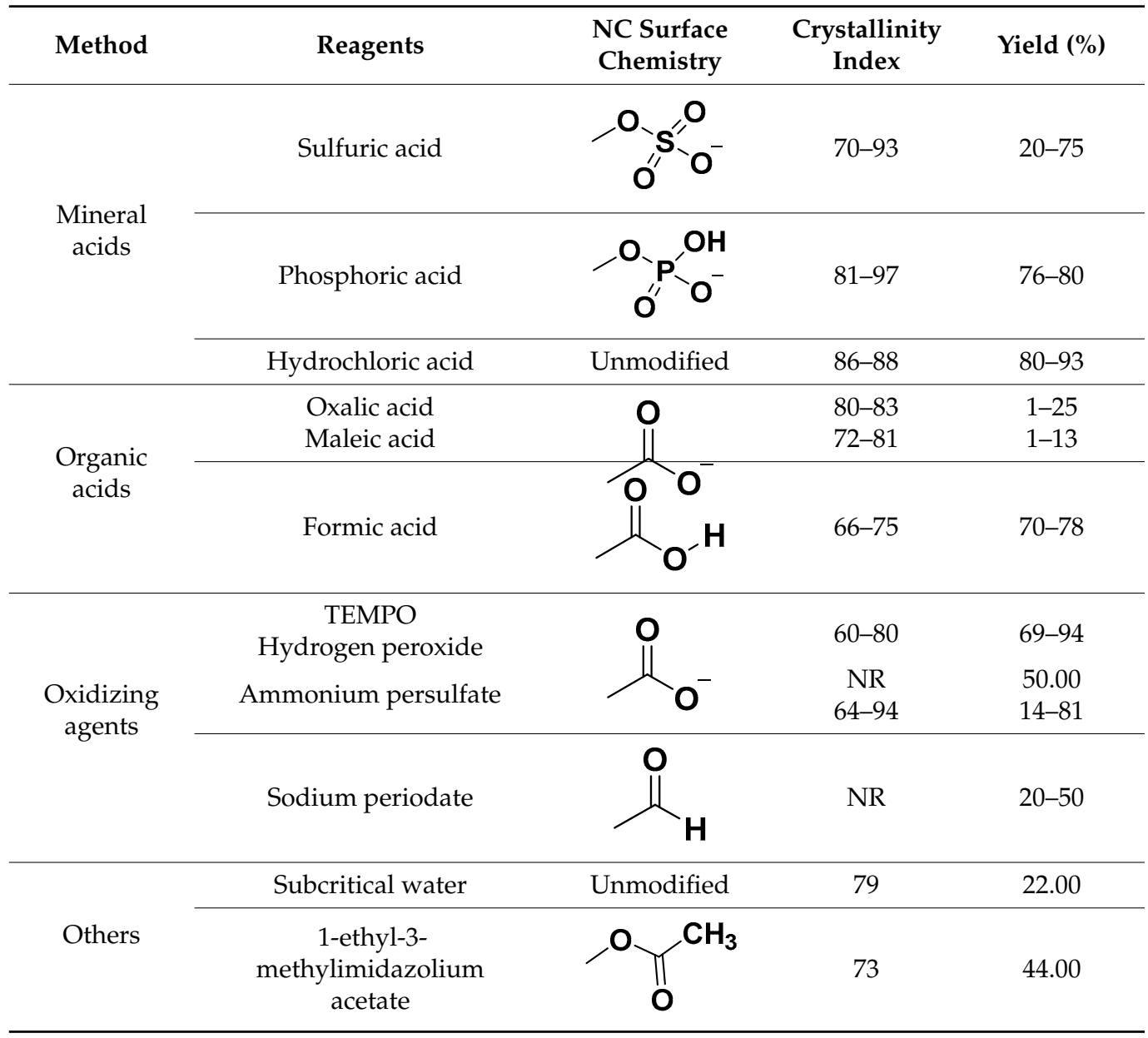

Recently, several studies have been attempted for utilizing organic acids to isolate CNs with new surface functionalities [20,26,27]. Several organic acids can be used, such as formic acid, maleic acid, oxalic acid, and citric acid [28-31]. In comparison to CNs made by sulfuric acid, the CNs obtained from these organic acid processes have a low degree of crystallinity, and the yield or colloidal stability is usually questionable. For example, CNs made with oxalic acid are colloidally stable, but the yield is low (less than $10 \%$ ) while CNs made with formic acid offer a high yield (30-40\%) but low colloidal stability and usually form aggregation [20,32]. Mixtures with mineral acids such as a mixture of nitric and hydrochloric acid have been used to produce CNs since the kinetics of cellulose hydrolysis is largely governed by free proton concentration while keeping the benefit of organic acid on the surface chemistry of CNs [33]. Overall, the use of mixture acids is a growing research area since it offers several advantages of high crystallinity, high yield, colloidal stability, and a variety of surface chemistry.

In addition to acid hydrolysis, CNs can be obtained from the oxidation process, enzymatic hydrolyses, or extraction with ionic liquid or deep eutectic solvent (DES) [26,34]. Of these methods, oxidation reactions yield the best results with a high crystalline, homogeneous, and consistent colloidal stability. Several oxidizing agents, including ammonium persulfate, hydroperoxide, (2,2,6,6-Tetramethylpiperidin-1-yl) oxyl (TEMPO) or sodium periodate, can be used. In the oxidation approach, $\mathrm{CNs}$ with carboxyl or aldehyde group offer great opportunities for surface functionalization that cannot be obtained with CNs with the sulfate group obtained from the process utilizing sulfuric acid. 


\section{Dimensions of Cellulose Nanomaterials}

In the 1950s, Ränby reported for the first time that colloidal suspensions can be produced from the hydrolysis of cellulose fibers catalyzed by concentrated sulfuric acid [9]. Transmission electron microscopy (TEM) revealed the presence of needle-shaped nanoparticles in dried suspensions, and later on, electron diffraction further demonstrated that these nanoparticles had the same crystalline structure as the original cellulose fibers. In 2017, the scientific community agreed to call it "cellulose nanocrystals or nanocrystal cellulose or cellulose nanomaterial" as a standard term referred to as microcrystals, whiskers, nanocrystals, nanoparticles, microcrystalline, or nanofibers (CNFs). The cellulose nanomaterial type can be classified based on the geometrical dimensions (length, L and width, w) [18,35]. In general, the width of the cellulose nanomaterial slightly varies while the length of the cellulose nanomaterial can be tuned up to 10 times on the $\mu \mathrm{m}$ scale, as shown in Table 2 . If the length of $\mathrm{CNs}$ is above $1 \mu \mathrm{m}$, then they are commonly named cellulose nanofibers (CNFs). Occasionally, cellulose nanomaterial produced by bacteria was called bacterial nanocellulose, BNC. Several cellulose nanomaterial types are caused by two main factors: (i) cellulosic sources and (ii) the isolation process of the cellulose nanomaterials, including any pretreatment steps applied to the cellulose microfibrils [3,23].

Table 2. Examples of CNs with the length (L) and width (w) from cellulosic sources measured by different methods.

\begin{tabular}{cccc}
\hline Source & Length $(\mathbf{n m})$ & Width $(\mathbf{n m})$ & Technique \\
\hline Bacterial & $100-1000$ & $10-50$ & TEM \\
\hline Soft wood & $100-200$ & $3-4$ & TEM \\
\hline Soft wood & $100-150$ & $4-5$ & AFM \\
\hline Hard wood & $140-150$ & $4-5$ & AFM \\
\hline Coconut husk fiber & $200-500$ & $10-15$ & TEM \\
\hline Pineapple crown & $100-400$ & $20-60$ & SEM \\
\hline Corn husk & 162 & 26.9 & TEM \\
\hline Banana pseudo-stem & $20-170$ & $0.6-6$ & TEM \\
\hline Doum tree & 435 & 5.2 & AFM \\
\hline
\end{tabular}

The dimensions (length, L, and width, w) of CNs vary widely as illustrated in Table 2. The morphological characteristics are usually studied by microscopy (transmission electron microscopy, TEM, atomic force microscopy, AFM, etc.) or light scattering techniques [23]. TEM images of CNs usually show aggregations of the CNs formed during the drying step in the sample preparation. Since CNs are a poorly conductive material, then to optimize the TEM analysis, a conductive layer such as carbon is usually needed to deposit on top of the CNs layer. However, the conductive layer could damage the CNs. In contrast to TEM, atomic force microscopy (AFM) can be utilized to analyze the morphology and topography of an insulating layer without any additional steps for samples preparation. Another benefit of AFM is the ability to conduct rapid analysis on a large area under ambient conditions at lengths scaled down to the angstrom level as shown in Figure 3. Besides, AFM was also utilized to rebuild the material in 3D structure and to measure CNs mechanical properties, for example, stiffness and adhesion or pull-off forces in contact mode.

Typical geometrical characteristics for CNs measured by AFM and TEM are summarized in Table 2. The reported width is generally in the range of a few to 50 nanometers, but the length of CNs spans in a larger window, from tens of nanometers to several micrometers. As a result, the aspect ratio defined as the length-to-width is in broad range ( 2 to a few hundred) strongly depending on the source of cellulosic materials and the extraction techniques [9,20]. For instance, CNs extracted from softwood are 3-4 nm in width and 100-200 $\mathrm{nm}$ in length, while CNs produced by bacteria are 10-50 $\mathrm{nm}$ in width 
and 1000-2000 $\mathrm{nm}$ in length. To optimize the performance of CNs, the aspect ratio should be carefully studied.

A

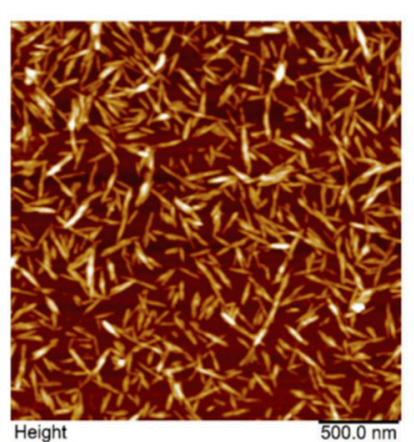

B

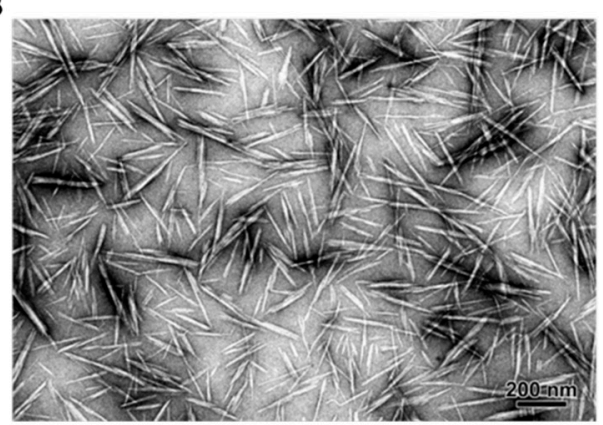

Figure 3. (A) AFM images of CNs deposited on mica and (B) TEM images of modified NC on the copper grid (reproduced with permission from author [36,37]).

\section{Surface Modification of Cellulose Nanomaterials}

The chemical functionality of CNs surfaces plays an essential role in utilizing the CNs in many applications. Due to the abundance of hydroxyl groups on the surface of $\mathrm{CNs}$, several chemical modifications have been studied, including esterification, oxidation, polymer grafting, etc. In addition, non-covalent surface modification via electrostatically adsorbing surfactants and polymer coating has also been studied. Generally speaking, the purpose of surface modification is to first (1) improve the dispersion of CNs by incorporating negative or positive functional groups on the surface and secondly (2) to new functional groups on its surface to enhance or generate the new possible application. The challenge for the surface functionalization of CNs is to conduct the process only on the surface of CNs while preserving the original morphology. Here we will shortly describe selective covalent techniques which are commonly used to modify the surface of CNs and more details could be found in the literature $[3,5,13,21]$.

\subsection{Chemical Functionalization of Cellulose Nanomaterials}

The most common and effective method of surface modification is through the direct chemical reaction in hydroxyl groups of cellulose surfaces. Several types of chemical reactions have been studied and briefly summarized in Scheme 2 . This chemical reaction can be categorized into two main classes: $[7,8,35]$. The first one is the oxidative reaction of hydroxyl groups, both at $\mathrm{C} 6$ position or in the AGU unit, which then transforms $\mathrm{OH}$ groups to $\mathrm{CHO}$ or $\mathrm{COOH}$ groups. The second method is to make an additional reaction with the $\mathrm{OH}$ groups which then converts it into $\mathrm{O}-\mathrm{R}$ where $\mathrm{R}$ is a chemical functional group such as $-\mathrm{SO}_{3} \mathrm{H}, \mathrm{CO}-\mathrm{OH}, \mathrm{CO}-\mathrm{R}^{1}$. We then briefly explain some main reactions below.

\subsubsection{Acetylation}

Acetylation, as illustrated in Scheme 2, involves the addition of acetic anhydride or dry acetic acid under the catalysis of mineral acid. Sassi et al. were the first to propose acetylation reactions occurring by the two main mechanisms [38]. In this case, toluene as a diluent was added to the reaction medium, a high degree of acetylation could be obtained and most importantly, the original morphology was maintained while in the diluent-free process, the acetylated functional group is soluble in the reaction medium consisting of acetic acid and an amount of mineral acid. We notice here that in the acetylation process, the acetylated functionalized cellulose nanomaterials usually undergo significant changes in morphology [35]. Cetin et al. reported that the original dimensions and crystallinity were preserved by catalyzing the reaction by vinyl carbonate [39]. Bulota and colleagues isolated cellulose nanofibers with a high degree of substitution using acetic anhydride for the acetylation associated with mechanical treatment [40]. Another concern in acetylation chemical reactions is the use of corrosive chemicals. Several methods using ionic liquids or 
enzyme lipases with acetic anhydride have been attempted to enhance the efficiency of the acetylation process [35].

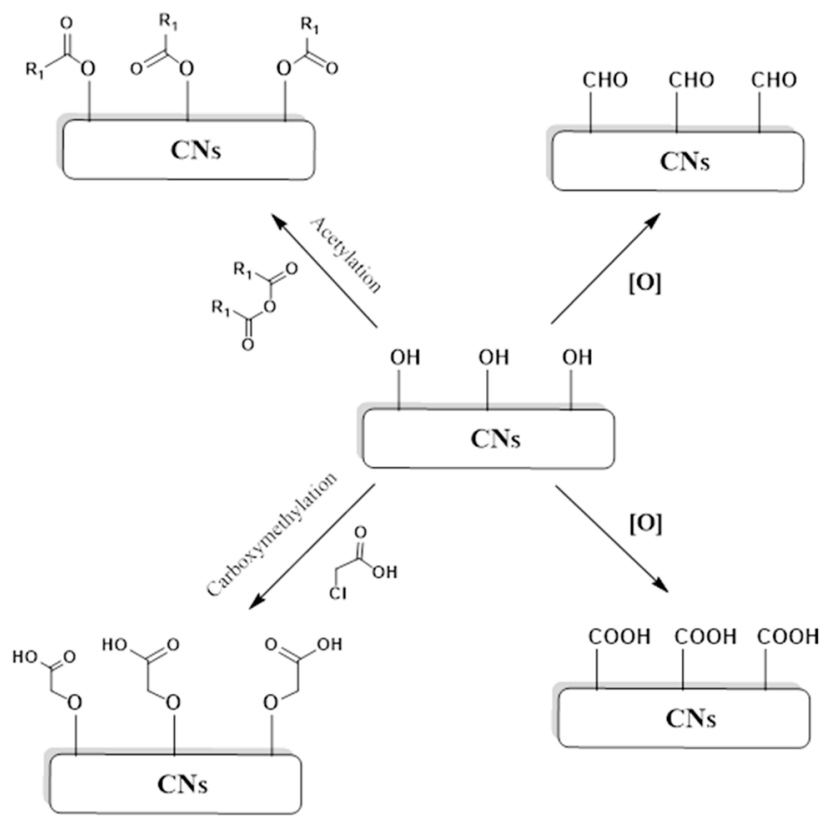

Scheme 2. Different chemical functionalization of cellulose nanomaterials reported in the literature.

\subsubsection{Carboxymethylation}

Carboxymethyl functional groups are incorporated onto the surfaces of CNs by the carboxymethylation reaction, as illustrated in Scheme 2. The reaction is usually performed with raw cellulose associated with a mechanical method to produce nanocellulose with high - $\mathrm{COOH}$ content on their surface, a one-step process to produce CNs. For example, Walberg et al. demonstrated the production of NFCs bypassing carboxymethylated cellulosic microfibers through a homogenizer, yielding NFCs with a diameter of 5-15 nm [41].

\subsubsection{Grafting on Cellulose}

Recently, grafting polymers onto cellulose nanomaterials appeared to be a promising approach to modifying the chemical and physical properties of the CNs used in biomedical applications. More details can be found in the literature [3,13]. Briefly, polymer grafting has been studied using three main approaches: grafting-to, grafting-from, and graftingthrough as illustrated in Figure 4. In the grafting-to approach, polymers are attached to the CNs via a chemical reaction between the reactive end group of the polymer and the hydroxyl groups of the CNs. In grafting-from or grafting-through, cellulose nanomaterials are usually functionalized with an initiator or an active, polymerizable species via the reaction with the hydroxyl group of the $\mathrm{CN}$. Afterward, monomers are added and then the polymerization is initiated. In comparison with the grafting-to approach, the graftingfrom and grafting-through are widely used for their high yield and flexibility in choosing monomers. The desired polymer-CNs product usually determines which polymerization approach should be used and was reviewed in detail by B. Thomas et al. [35].

Grafting onto cellulose has also been extended to produce hybrid materials based on CNs such as cellulose-metal-organic frameworks (celloMOFs) [42,43], $\mathrm{TiO}_{2} /$ nanocellulose [44], graphene oxide/nitrocellulose [45]. For example, Aji P. Mathew et al. reported the ability to use nanocellulose as a platform for the in-situ formation of metal oxide nanoparticles on its surface as illustrated in Figure 5 [46,47]. The authors demonstrated that carboxylated cellulose nanofibril-based films can spontaneously grow functional metal oxide nanoparticles, for example, $\mathrm{Cu}_{2} \mathrm{O}$, during the adsorption of $\mathrm{Cu}(\mathrm{II})$ ions, without any further chemical or temperature treatment. By monitoring the reaction in real-time, they suggested that the first step in the nanoparticle formation is the absorption of these 
metal ions onto the CNs and then followed up by the nanoparticle formation catalyzed by aldehyde groups in the drying process of these wetting films. These hybrid nanomaterials can not only remove dye waste but also be used as antimicrobial materials [46].

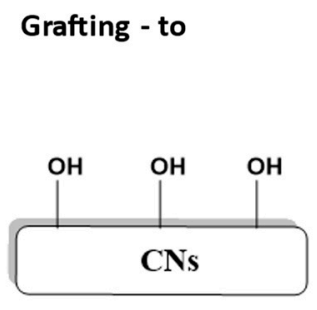

Grafting - from
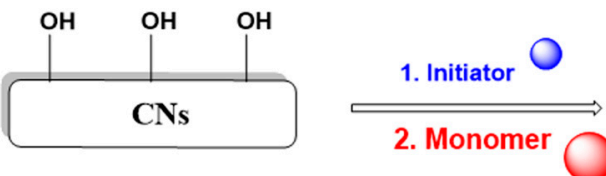

Grafting - through
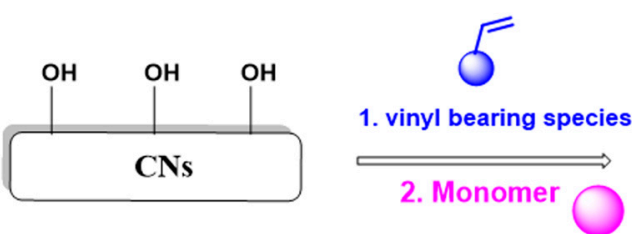
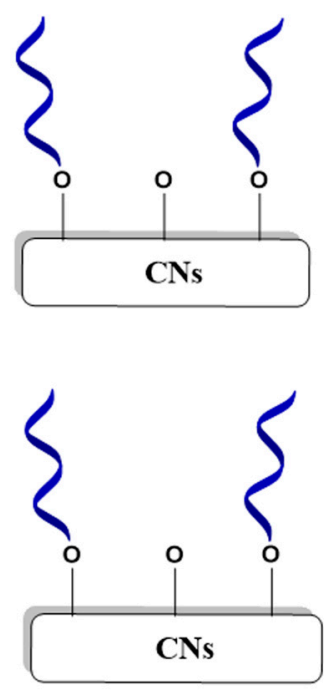

Figure 4. Scheme showing grafting-from, grafting-to and grafting-Through of polymers onto CNs.
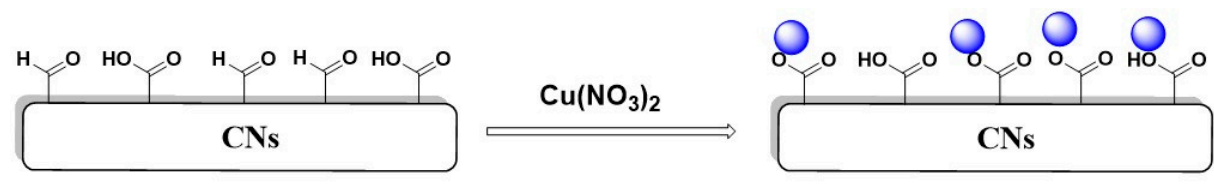

$\mathrm{Cu}_{2} \mathrm{O}$

Antimicrobial properties

- Dye removal

Figure 5. Conceptual scheme showing the in-situ formation of $\mathrm{Cu}_{2} \mathrm{O}$ nanoparticles on $\mathrm{CNs}$ films with dye removal and antimicrobial properties. The scheme presents the reaction between $\mathrm{Cu}$ (II) adsorbed on the $\mathrm{CNs}$ surface with - $\mathrm{CHO}$ functional group of the $\mathrm{CNs}$ to form $\mathrm{Cu}_{2} \mathrm{O}-\mathrm{NPS}$.

\section{Application of Cellulose Nanomaterials}

\subsection{Absorbents in Water Treatment}

It is widely agreed that the water crisis will quickly become a global pandemic shortly. Safe, drinkable water is considered one of the top requirements for defining the standard of living of human beings. However, the rising contaminated water is becoming a common threat worldwide and is highlighted as one of the significant challenges shortly [6].

Recent advances in nanotechnology have proposed several approaches to decontaminate and then convert polluted waters into safe, drinkable water [6,48,49] Among these approaches, the scientific community has made tremendous efforts on the utilization of nanomaterials as an adsorbent. Nanomaterials, especially metallic oxide nanoparticles, have been investigated in purifying polluted, degraded waters such as waste waters and saline waters. For example, titanium oxide $\left(\mathrm{TiO}_{2}\right)$, zinc oxide $(\mathrm{ZnO})$, and silver $(\mathrm{Ag})$ 
nanoparticles were considered not only as good adsorbents but also as antimicrobial materials and photocatalysts. However, these nanoparticles could accumulate in both living and nonliving systems which could eventually trigger unpredictable changes in natural ecosystems and eventually on human beings' health [49]. For example, it is widely agreed that silver nanoparticles can be extremely toxic and hazardous to human beings caused by their dissolution, aggregation, oxidation, and sulfidation. In contrast to these nanoparticles, CNs, produced from cellulose, have the advantages of being ubiquitous, nontoxic, and exceptional adsorbents. Furthermore, the surface chemistry of nano cellulosic materials can easily be modified to enhance the adsorbent properties. These features make CNs an ideal bio-adsorbent.

Removal of heavy metals by adsorbent has received great effect by its high efficiency and simplicity. CNs have been extensively investigated to remove heavy metals thanks to their low-cost absorbent, environmentally friendly, safe nanomaterials $[46,49]$. It is known that the carboxylic functional groups of CNs enable the adsorption of cationic species from aqueous solutions caused by the electrostatic force between the negative charge of carboxylate groups and the metallic cations. Furthermore, the hydroxyl group on the AGU unit of CNs can chemically be transformed to other functional groups such as amine or thiol to enhance the heavy metal adsorption capacity. As expected, CNs were reported to effectively coordinate and absorb several heavy metal cations, for example, Cu (II), Co (II), $\mathrm{Cd}$ (II), Ni (II), Pb (II), As (V), and Cr (VI) cation. Jafari et al. also demonstrated the ability to efficiently adsorb gold from a chloride solution (98\%) [50]. Ma et al. further reported the ability of $\mathrm{CNs}$ to remove radioactive uranyl ions (UO22+), from solutions caused by the affinity of UO22+ ions with the carboxylate groups, and the maximum adsorption capacity $167 \mathrm{mg} \cdot \mathrm{g}^{-1}$ is $2-3$ times greater than traditional adsorbents (e.g., silica particle, montmorillonite) [51].

Copper (II) cation is a common pollutant in industrial wastewater as copper metal is being used in industrial production. A small amount of copper is essential for human health, however excess amounts (above $1.3 \mathrm{mg} / \mathrm{L}$ ) can cause adverse health effects such as hemolysis and anemia. Kardam et al. reported the low adsorption capacity $\left(<20 \mathrm{mg} \cdot \mathrm{g}^{-1}\right)$ of native nanocellulose fiber (NCF) which is assigned to the low affinity of hydroxyl, $\mathrm{OH}$, group concerning $\mathrm{Cu}(\mathrm{II})$ ion [52]. To enhance the adsorption capacity or the affinity with metal ions, a general method is to transform the $\mathrm{OH}$ group into active sites for metal adsorption (such as carboxyl, sulfonic, or phosphoryl groups). Liu et al. reported that CNs with a carboxylate content of $1.5 \mathrm{mmol} \cdot \mathrm{g}^{-1}$ produced by TEMPO oxidation had a $\mathrm{Cu}$ (II) adsorption capacity of $75 \mathrm{mg} \cdot \mathrm{g}^{-1}$, which is better than native CNs and many other nanomaterial adsorbents (such as modified $\mathrm{TiO}_{2}$, carbon nanotube, and granular activated carbon) [53]. Its enhanced performance was widely agreed caused by the strong affinity of the carboxylate groups on the surface of CNs. It was later proven by Zhang et al. that the $\mathrm{Cu}$ (II) absorption capacity linearly increases concerning the carboxylate contents. Sehaqui et al. reported that by optimizing the $\mathrm{pH}$ and $\mathrm{CNs}$ surface, the maximum $\mathrm{Cu}$ (II) capacity of the TEMPO-oxidation CNs was $135 \mathrm{mg} \cdot \mathrm{g}^{-1}$, and more importantly, the adsorbent can be easily regenerated by acidic washing [54].

Carboxylation and carboxymethylation are efficient approaches to enhance the content of $\mathrm{COOH}$ groups on the surface of CNs. Qin et al. recently reported that carboxymethylated nanocellulose fibrils were produced with a carboxylate content up to $2.7 \mathrm{mmol} \cdot \mathrm{g}^{-1}$. As predicted, the maximum adsorption capacity of the carboxymethylated CNs was up to $115.3 \mathrm{mg} \cdot \mathrm{g}^{-1}$ at $\mathrm{pH} \sim 5$ [55].

In addition, the adsorption capacity of adsorbent $\mathrm{CNs}$ can be greatly increased by changing the architecture of the adsorbent. For example, Karim et al. reported the record $\mathrm{Cu}$ (II) adsorption capacity, $374 \mathrm{mg} \mathrm{g}^{-1}$, using CNs membranes based on TEMPO oxidation which is three-times higher than many other bio-adsorbents (usually less than $100 \mathrm{mg} \mathrm{g}^{-1}$ ) [56]. This extraordinary performance could result from the large active surface area and high concentration of the carboxylate groups. 


\subsection{Antimicrobial Materials}

Biodegradable and renewable cellulose nanomaterials have recently proven to be great candidates for antimicrobial materials against microbes in healthcare protective gears, food packages, and ultrafiltration membranes $[57,58]$. Since native cellulose nanomaterials are usually not considered antimicrobial agents, then cellulose nanomaterials utilized as antimicrobial materials must be prepared through two main approaches. The first approach is to functionalize the surface of cellulose nanomaterials with antimicrobial functional groups such as the aldehyde group and quaternary ammonium [58]. Aldehyde functionalized cellulose nanomaterials can be prepared through the oxidation process catalyzed by a periodate sodium oxidant. Quaternary functional groups such as imidazolium, pyridinium, or 4-vinyl pyridine are usually considered low toxicity and environmentally friendly. It is known that viruses and many other microbe species have a negative charge on their surface, and as a result, cellulose nanomaterial associated with the quaternary group will improve the electrostatic forces, in other words, its antimicrobial properties. The second approach is to combine cellulose nanomaterials with antimicrobial agents such as nanoparticles (e.g., $\mathrm{Au}, \mathrm{Ag}, \mathrm{Cu}, \mathrm{Cu}_{2} \mathrm{O}$ ), chitosan, silanes, chlorine, and antibiotics, to produce hybrid nanocomposite. There are several antibiotics for example gentamycin, chloromycetin, or allicin which are usually utilized for packaging and biomedical applications while inorganic nanoparticles are widely used for bacteria.

The virus is the smallest in size (diameter in the range of 20 to $400 \mathrm{~nm}$ ) and it is the most difficult to deal with. For example, on 12 March 2020, the World Health Organization (WHO) declared the COVID-19 outbreak as a pandemic that caused serious threats to humanity. COVID-19 infection is caused by a novel betacoronavirus, named SARS CoV2. This virus continues through airborne circulation and as a result, infected cases have exponentially increased and few signs of remission were recorded though the vaccinated rate was ramped up recently. Many countries are requiring a surgical face mask as a mandate, hand hygiene, and social distancing to minimize the spread of this virus. A great, emerging challenge associated along with COVID-19 is the effect of face mask waste on human health and the marine ecosystem. We note here that all available surgical face masks are non-biodegradable and hazardous since they are normally made of petroleum-based polymers. It is urgent to produce a virus removal filter that could work effectively, but equally importantly, it must be biodegradable and affordable. To our knowledge, the exploration of cellulose nanomaterials as virus removal for a degradable filter has recently seen some efforts.

In the filtration process, two main parameters will influence the efficiency. The first one is the architecture of a filter, including pore size in comparison to the size of a virus, thickness, number of filter layers, and the design of the filter [59]. The size exclusion filtration is widely used due to its flexibility, ease of use and nontoxic chemicals for inactivation. Secondly, the efficiency of virus removal can be greatly improved by strengthening the interaction force between the surface charge of the virus and the nitrocellulose filters. For example, the coronavirus and others are widely known to have a negatively charged surface. As a result, introducing functional groups with a positive charge on $\mathrm{CNs}$ will enhance the possibilities of virus removal. This approach was proven as an effective method by several reports. For instance, Mi et al. reported that incorporating nanocellulose with a positively charged guanidine group can enhance the adsorption of porcine parvovirus and sindbis virus from water by forming ionic and hydrogen bonds with the proteins and lipids on the virus surface [60].

\section{Challenges}

In summary, in this mini-review, we highlight cellulose nanomaterials' most important chemical and physical aspects and some interesting CNs applications. Cellulose nanomaterial is interesting for two main reasons: firstly, it is a sustainable, renewable, and more importantly biodegradable biomaterial that can be produced from a wide range of natural materials including biomass waste. An increase in utilizing this biodegradable material 
could help to manage the waste, eliminating pollution on the earth. Secondly, it has several excellent properties and thus can be incorporated into a variety of materials applied in packaging, films, and paper, but also for much more surprising domains: biomedicine, microelectronics, catalyst support, adsorbents, and antimicrobial material. The broader and more versatile properties result from their size at the nanoscale, surface chemistry and the assembly of CNs into nanostructure materials. Through their wide range of applications, there is a need to improve our understanding of the chemical structure of CNs and its interaction within hybrid, composite, and formulated products. To optimize the performance of materials that incorporate $\mathrm{CNs}$, researchers must select CNCs with suitable surface chemistry, surface charge density, crystallinity, and aspect ratio, as each target application requires a different set of $\mathrm{CNs}$ properties.

The CNs have been reported as effective heavy-metal adsorbents by several works; however, several scientific questions and improvements still need to be assessed. Most of the examples reported in the literature assigned good heavy metal adsorption to the existence of -COOH groups. However, the lack of systematic studies made it a challenge to understand the relationship. Importantly, there are several chemical groups, such as thiol, -SH, or amine, $\mathrm{NH}_{2}$, which are usually considered to enhance adsorption. As a result, CNs functionalized by thiol or amine must be used to optimize the adsorption. In addition, the active surface area of CNs or the design of CNs film must be studied carefully in order to understand the kinetic of the adsorption process. The application of CNs as antimicrobial agents is still very limited and therefore more research is needed. For example, the CNs as support must be chemically bonded with antimicrobial agents in order to enhance the stability and durability. The CNs could also be used in combination with antimicrobial agents derived from nature to enhance the antimicrobial properties.

The surface chemistry of CNs plays an important role in enhancing their adsorption and antimicrobial properties. In this review, several approaches were presented; however, these approaches usually consist of several steps, such as isolation of CNs, then chemical functionalization, and polymerization. These steps made the process less environmentally friendly, sustainable and efficient. As a result, there is a need to compile these steps into single steps in order to generate functionalized-CNs which can be used as adsorbents or antimicrobial materials.

Author Contributions: Conceptualization, Q.N.V. and Y.D.H.; methodology, Q.N.V., H.T.P. and N.K.T.; investigation, P.T.A.T., Q.N.V. and H.T.P.; data curation, H.T.P. and Y.D.H.; writing-original draft preparation, Q.N.V., Y.D.H., P.T.A.T. and H.T.P.; writing—review and editing, Q.N.V., N.K.T., H.T.P. and Y.D.H. All authors have read and agreed to the published version of the manuscript.

Funding: This research was funded by the Vietnam Academy of Science and Technology, grant number VAST TĐNSH 0.00/20-21.

Institutional Review Board Statement: Not applicable.

Informed Consent Statement: Not applicable.

Data Availability Statement: Not applicable.

Conflicts of Interest: The authors declare no conflict of interest.

\section{References}

1. Li, T.; Chen, C.; Brozena, A.H.; Zhu, J.Y.; Xu, L.; Driemeier, C.; Dai, J.; Rojas, O.J.; Isogai, A.; Wågberg, L.; et al. Developing fibrillated cellulose as a sustainable technological material. Nature 2021, 590, 47-56. [CrossRef] [PubMed]

2. $\quad$ Chen, W.; Yu, H.; Lee, S.-Y.; Wei, T.; Li, J.; Fan, Z. Nanocellulose: A promising nanomaterial for advanced electrochemical energy storage. Chem. Soc. Rev. 2018, 47, 2837-2872. [CrossRef] [PubMed]

3. Zhu, H.; Luo, W.; Ciesielski, P.N.; Fang, Z.; Zhu, J.Y.; Henriksson, G.; Himmel, M.E.; Hu, L. Wood-Derived Materials for Green Electronics, Biological Devices, and Energy Applications. Chem. Rev. 2016, 116, 9305-9374. [CrossRef] [PubMed]

4. Jorfi, M.; Foster, E.J. Recent advances in nanocellulose for biomedical applications. J. Appl. Polym. Sci. 2015, 132, 41719. [CrossRef]

5. De France, K.; Zeng, Z.; Wu, T.; Nyström, G. Functional Materials from Nanocellulose: Utilizing Structure-Property Relationships in Bottom-Up Fabrication. Adv. Mater. 2021, 33, e2000657. [CrossRef] 
6. Mautner, A. Nanocellulose water treatment membranes and filters: A review. Polym. Int. 2020, 69, 741-751. [CrossRef]

7. Yang, X.; Biswas, S.K.; Han, J.; Tanpichai, S.; Li, M.; Chen, C.; Zhu, S.; Das, A.K.; Yano, H. Surface and Interface Engineering for Nanocellulosic Advanced Materials. Adv. Mater. 2020, 33, 2002264. [CrossRef]

8. Heise, K.; Kontturi, E.; Allahverdiyeva, Y.; Tammelin, T.; Linder, M.B.; Nonappa; Ikkala, O. Nanocellulose: Recent Fundamental Advances and Emerging Biological and Biomimicking Applications. Adv. Mater. 2021, 33, 2004349. [CrossRef] [PubMed]

9. Habibi, Y.; Lucia, L.A.; Rojas, O.J. Cellulose Nanocrystals: Chemistry, Self-Assembly, and Applications. Chem. Rev. 2010, 110, 3479-3500. [CrossRef]

10. Raj, V.; Raorane, C.J.; Lee, J.H.; Lee, J. Appraisal of Chitosan-Gum Arabic-Coated Bipolymeric Nanocarriers for Efficient Dye Removal and Eradication of the Plant Pathogen Botrytis cinerea. ACS Appl. Mater. Interfaces 2021, 13, 47354-47370. [CrossRef]

11. Raj, V.; Lee, J.H.; Shim, J.J.; Lee, J. Recent findings and future directions of grafted gum karaya polysaccharides and their various applications: A review. Carbohydr. Polym. 2021, 258, 117687. [CrossRef]

12. Choudhury, R.R.; Sahoo, S.K.; Gohil, J.M. Potential of bioinspired cellulose nanomaterials and nanocomposite membranes thereof for water treatment and fuel cell applications. Cellulose 2020, 27, 6719-6746. [CrossRef]

13. de France, K.J.; Hoare, T.; Cranston, E.D. Review of Hydrogels and Aerogels Containing Nanocellulose. Chem. Mater. 2017, 29, 4609-4631. [CrossRef]

14. Sharma, A.; Thakur, M.; Bhattacharya, M.; Mandal, T.; Goswami, S. Commercial application of cellulose nano-composites-A review. Biotechnol. Rep. 2019, 21, e00316. [CrossRef] [PubMed]

15. Trache, D.; Hussin, M.H.; Haafiz, M.K.M.; Thakur, V.K. Recent progress in cellulose nanocrystals: Sources and production. Nanoscale 2017, 9, 1763-1786. [CrossRef]

16. Varma, R.S. Biomass-Derived Renewable Carbonaceous Materials for Sustainable Chemical and Environmental Applications. ACS Sustain. Chem. Eng. 2019, 7, 6458-6470. [CrossRef]

17. Rajinipriya, M.; Nagalakshmaiah, M.; Robert, M.; Elkoun, S. Importance of Agricultural and Industrial Waste in the Field of Nanocellulose and Recent Industrial Developments of Wood Based Nanocellulose: A Review. ACS Sustain. Chem. Eng. 2018, 6, 2807-2828. [CrossRef]

18. Klemm, D.; Kramer, F.; Moritz, S.; Lindström, T.; Ankerfors, M.; Gray, D.; Dorris, A. Nanocelluloses: A New Family of Nature-Based Materials. Angew. Chem. Int. Ed. 2011, 50, 5438-5466. [CrossRef] [PubMed]

19. Akhtar, S. Thermally Stable, Dispersible Cellulose Nanocrystals. U.S. Patent No. 11,014,993, 25 May 2021.

20. Vanderfleet, O.M.; Cranston, E.D. Production routes to tailor the performance of cellulose nanocrystals. Nat. Rev. Mater. 2021, 6, 124-144. [CrossRef]

21. Fink, H.P.; Hofmann, D.; Philipp, B. Some aspects of lateral chain order in cellulosics from X-ray scattering. Cellulose 1995, 2, 51-70. [CrossRef]

22. Klemm, D.; Heublein, B.; Fink, H.P.; Bohn, A. Cellulose: Fascinating Biopolymer and Sustainable Raw Material. Angew. Chemie Int. Ed. 2005, 44, 3358-3393. [CrossRef]

23. Foster, E.J.; Moon, R.J.; Agarwal, U.P.; Bortner, M.J.; Bras, J.; Camarero-Espinosa, S.; Chan, K.J.; Clift, M.J.D.; Cranston, E.D.; Eichhorn, S.J.; et al. Current characterization methods for cellulose nanomaterials. Chem. Soc. Rev. 2018, 47, 2609-2679. [CrossRef]

24. Espinosa, S.C.; Kuhnt, T.; Foster, E.J.; Weder, C. Isolation of Thermally Stable Cellulose Nanocrystals by Phosphoric Acid Hydrolysis. Biomacromolecules 2013, 14, 1223-1230. [CrossRef] [PubMed]

25. Vanderfleet, O.M.; Osorio, D.A.; Cranston, E.D. Optimization of cellulose nanocrystal length and surface charge density through phosphoric acid hydrolysis. Philos. Trans. R. Soc. A Math. Phys. Eng. Sci. 2018, 376, 20170041. [CrossRef] [PubMed]

26. Haron, G.A.S.; Mahmood, H.; Noh, M.H.; Alam, M.Z.; Moniruzzaman, M. Ionic Liquids as a Sustainable Platform for Nanocellulose Processing from Bioresources: Overview and Current Status. ACS Sustain. Chem. Eng. 2021, 9, 1008-1034. [CrossRef]

27. Nagarajan, K.J.; Balaji, A.N.; Rajan, S.T.K.; Ramanujam, N.R. Preparation of bio-eco based cellulose nanomaterials from used disposal paper cups through citric acid hydrolysis. Carbohydr. Polym. 2020, 235, 115997. [CrossRef] [PubMed]

28. Du, H.; Liu, C.; Mu, X.; Gong, W.; Lv, D.; Hong, Y.; Si, C.; Li, B. Preparation and characterization of thermally stable cellulose nanocrystals via a sustainable approach of FeCl3-catalyzed formic acid hydrolysis. Cellulose 2016, 23, 2389-2407. [CrossRef]

29. Chen, L.; Zhu, J.Y.; Baez, C.; Kitin, P.; Elder, T. Highly thermal-stable and functional cellulose nanocrystals and nanofibrils produced using fully recyclable organic acids. Green Chem. 2016, 18, 3835-3843. [CrossRef]

30. Kontturi, E.; Laaksonen, P.; Linder, M.B.; Nonappa; Gröschel, A.H.; Rojas, O.J.; Ikkala, O. Advanced Materials through Assembly of Nanocelluloses. Adv. Mater. 2018, 30, 1703779. [CrossRef]

31. Henschen, J.; Li, D.; Ek, M. Preparation of cellulose nanomaterials via cellulose oxalates. Carbohydr. Polym. 2019, 213, 208-216. [CrossRef]

32. Yu, H.; Abdalkarim, S.Y.H.; Zhang, H.; Wang, C.; Tam, K.C. Simple Process To Produce High-Yield Cellulose Nanocrystals Using Recyclable Citric/Hydrochloric Acids. ACS Sustain. Chem. Eng. 2019, 7, 4912-4923. [CrossRef]

33. He, X.; Luzi, F.; Yang, W.; Xiao, Z.; Torre, L.; Xie, Y.; Puglia, D. Citric Acid as Green Modifier for Tuned Hydrophilicity of Surface Modified Cellulose and Lignin Nanoparticles. ACS Sustain. Chem. Eng. 2018, 6, 9966-9978. [CrossRef]

34. Xia, Q.; Chen, C.; Yao, Y.; Li, J.; He, S.; Zhou, Y.; Li, T.; Pan, X.; Yao, Y.; Hu, L. A strong, biodegradable and recyclable lignocellulosic bioplastic. Nat. Sustain. 2021, 4, 627-635. [CrossRef]

35. Thomas, B.; Raj, M.C.; Athira, K.B.; Rubiah, M.H.; Joy, J.; Moores, A.; Drisko, G.L.; Sanchez, C. Nanocellulose, a Versatile Green Platform: From Biosources to Materials and Their Applications. Chem. Rev. 2018, 118, 11575-11625. [CrossRef] 
36. Tanpichai, S.; Oksman, K. Aligned-porous-structured poly(vinyl alcohol) foams with cellulose nanocrystals. AIP Conf. Proc. 2018, 2010, 20007. [CrossRef]

37. Mariano, M.; El-Kissi, N.; Dufresne, A. Cellulose nanocrystals and related nanocomposites: Review of some properties and challenges. J. Polym. Sci. Part B Polym. Phys. 2014, 52, 791-806. [CrossRef]

38. Sassi, J.F.; Chanzy, H. Ultrastructural aspects of the acetylation of cellulose. Cellulose 1995, 2, 111-127. [CrossRef]

39. Çetin, N.S.; Tingaut, P.; Özmen, N.; Henry, N.; Harper, D.; Dadmun, M.; Sèbe, G. Acetylation of Cellulose Nanowhiskers with Vinyl Acetate under Moderate Conditions. Macromol. Biosci. 2009, 9, 997-1003. [CrossRef]

40. Bulota, M.; Kreitsmann, K.; Hughes, M.; Paltakari, J. Acetylated microfibrillated cellulose as a toughening agent in poly(lactic acid). J. Appl. Polym. Sci. 2012, 126, E449-E458. [CrossRef]

41. Wågberg, L.; Decher, G.; Norgren, M.; Lindström, T.; Ankerfors, M.; Axnäs, K. The Build-Up of Polyelectrolyte Multilayers of Microfibrillated Cellulose and Cationic Polyelectrolytes. Langmuir 2008, 24, 784-795. [CrossRef] [PubMed]

42. Abdelhamid, H.N.; Mathew, A.P. Cellulose-metal organic frameworks (CelloMOFs) hybrid materials and their multifaceted Applications: A review. Coord. Chem. Rev. 2022, 451, 214263. [CrossRef]

43. Abdelhamid, H.N.; Mathew, A.P. In-situ growth of zeolitic imidazolate frameworks into a cellulosic filter paper for the reduction of 4-nitrophenol. Carbohydr. Polym. 2021, 274, 118657. [CrossRef]

44. Nair, S.S.; Chen, J.; Slabon, A.; Mathew, A.P. Converting cellulose nanocrystals into photocatalysts by functionalisation with titanium dioxide nanorods and gold nanocrystals. RSC Adv. 2020, 10, 37374-37381. [CrossRef]

45. Liu, P.; Zhu, C.; Mathew, A.P. Mechanically robust high flux graphene oxide-Nanocellulose membranes for dye removal from water. J. Hazard. Mater. 2019, 371, 484-493. [CrossRef] [PubMed]

46. Valencia, L.; Kumar, S.; Nomena, E.M.; Salazar-Alvarez, G.; Mathew, A.P. In-Situ Growth of Metal Oxide Nanoparticles on Cellulose Nanofibrils for Dye Removal and Antimicrobial Applications. ACS Appl. Nano Mater. 2020, 3, 7172-7181. [CrossRef]

47. Valencia, L.; Nomena, E.M.; Monti, S.; Arbelaez, W.J.R.; Mathew, A.P.; Kumar, S.; Velikov, K.P. Multivalent ion-induced re-entrant transition of carboxylated cellulose nanofibrils and its influence on nanomaterials' properties. Nanoscale 2020, 12, 15652-15662. [CrossRef] [PubMed]

48. Carpenter, A.W.; de Lannoy, C.-F.; Wiesner, M.R. Cellulose Nanomaterials in Water Treatment Technologies. Environ. Sci. Technol. 2015, 49, 5277-5287. [CrossRef] [PubMed]

49. Ray, S.S.; Iroegbu, A.O.C. Nanocellulosics: Benign, Sustainable, and Ubiquitous Biomaterials for Water Remediation. ACS Omega 2021, 6, 4511-4526. [CrossRef]

50. Jafari, S.; Wilson, B.P.; Hakalahti, M.; Tammelin, T.; Kontturi, E.; Lundström, M.; Sillanpää, M. Recovery of Gold from Chloride Solution by TEMPO-Oxidized Cellulose Nanofiber Adsorbent. Sustainability 2019, 11, 1406. [CrossRef]

51. Ma, H.; Hsiao, B.S.; Chu, B. Ultrafine Cellulose Nanofibers as Efficient Adsorbents for Removal of UO22+ in Water. ACS Macro Lett. 2011, 1, 213-216. [CrossRef]

52. Kardam, A.; Raj, K.R.; Srivastava, S.; Srivastava, M.M. Nanocellulose fibers for biosorption of cadmium, nickel, and lead ions from aqueous solution. Clean Technol. Environ. Policy 2014, 16, 385-393. [CrossRef]

53. Liu, P.; Garrido, B.; Oksman, K.; Mathew, A.P. Adsorption isotherms and mechanisms of Cu(II) sorption onto TEMPO-mediated oxidized cellulose nanofibers. RSC Adv. 2016, 6, 107759-107767. [CrossRef]

54. Sehaqui, H.; De Larraya, U.P.; Liu, P.; Pfenninger, N.; Mathew, A.P.; Zimmermann, T.; Tingaut, P. Enhancing adsorption of heavy metal ions onto biobased nanofibers from waste pulp residues for application in wastewater treatment. Cellulose 2014, 21, 2831-2844. [CrossRef]

55. Qin, F.; Fang, Z.; Zhou, J.; Sun, C.; Chen, K.; Ding, Z.; Li, G.; Qiu, X. Efficient Removal of Cu ${ }^{2+}$ in Water by Carboxymethylated Cellulose Nanofibrils: Performance and Mechanism. Biomacromolecules 2019, 20, 4466-4475. [CrossRef]

56. Karimi, M.A.; Bahoosh, S.G.; Valášek, M.; Bürkle, M.; Mayor, M.; Pauly, F.; Scheer, E. Identification of the current path for a conductive molecular wire on a tripodal platform. Nanoscale 2016, 8, 10582-10590. [CrossRef] [PubMed]

57. Fu, L.; Zhang, J.; Yang, G. Present status and applications of bacterial cellulose-based materials for skin tissue repair. Carbohydr. Polym. 2013, 92, 1432-1442. [CrossRef] [PubMed]

58. Norrrahim, M.N.F.; Nurazzi, N.M.; Jenol, M.A.; Farid, M.A.A.; Janudin, N.; Ujang, F.A.; Yasim-Anuar, T.A.T.; Najmuddin, S.U.F.S.; Ilyas, R.A. Emerging development of nanocellulose as an antimicrobial material: An overview. Mater. Adv. 2021, 2, $3538-3551$. [CrossRef]

59. Metreveli, G.; Wågberg, L.; Emmoth, E.; Belák, S.; Strømme, M.; Mihranyan, A. A Size-Exclusion Nanocellulose Filter Paper for Virus Removal. Adv. Healthc. Mater. 2014, 3, 1546-1550. [CrossRef]

60. Mi, X.; Albukhari, S.M.; Heldt, C.L.; Heiden, P.A. Virus and chlorine adsorption onto guanidine modified cellulose nanofibers using covalent and hydrogen bonding. Carbohydr. Res. 2020, 498, 108153. [CrossRef] 